\title{
A COMPLEXITY PERSPECTIVE ON CSR AND SUSTAINABILITY: THEORY AND A LONGITUDINAL CASE STUDY
}

\author{
TERRY B. PORTER \& RANDALL REISCHER \\ The Maine Business School, University of Maine, USA.
}

\begin{abstract}
Corporate social responsibility (CSR) has become standard practice for many if not most of the business organizations today. Extant CSR research largely assumes positivist, linear, and reductionist epistemologies and frequently invokes a 'systems theory' that is unspecified, seemingly taken for granted. The dominance of this conventional approach obscures or conflates significant dynamics that complexity systems theory reveals. This paper develops and compares an emerging complexity theory view of CSR with the more conventional approach. A longitudinal quantitative case study then tests competing hypotheses, permitting an examination of the efficacy of each approach for understanding CSR adoption processes, to our knowledge for the first time.

Two longitudinal surveys of employee attitudes were administered during, and one year after, the rollout of an internal CSR initiative in a Welsh civil society organization. Hypothesis testing led to three anomalous results. First, expected linear increases in employee wellbeing did not persist; second, neither expected nor latent attitude constructs were in evidence; and finally, the only attitude items to increase significantly over time were related to tangible social action and interaction, over and above changes in thinking and beliefs. Complexity theory offers alternative explanations of these results, explanations which we propose be developed to provide a more complete understanding of CSR practice and theory.

Keywords: company responsibility, complexity theory, corporate social responsibility, high performance work systems, modern working practices, resilience, strategic human resources management, sustainability, sustainability adoption processes.
\end{abstract}

\section{INTRODUCTION}

Corporate social responsibility (CSR) is becoming ubiquitous in business organizations. Documented benefits to companies include improved financial performance, enhanced legitimacy and image, product quality, operational efficiencies, decreased risk, and attractiveness to investors, among others [1]. For employees, it has been found that perceived intrinsic rewards, trust in managers, decreased stress, job satisfaction, personal wellbeing, and willingness to invest 'discretionary effort' increase when greater attention and effort is put into CSR [2]. With so much good news, managers are inquiring into how to implement an effective CSR program. Yet here the research falls short, for very little has been studied or learned about internal employee-centric processes related to CSR.

Our aim is to examine the internal processes that lie behind sustainability adoption decisions, both theoretically and empirically. Our literature review finds two distinct perspectives to be in play, the taken-for-granted linear systems approach, and an emerging viewpoint based in complexity theory. From here we develop a set of opposing hypotheses, which we then test in a longitudinal study of a sustainability focused human resources initiative in a UK organization. Thus, we have a means of comparing quantitative findings from each perspective, enabling comment on whether and how each approach contributes to CSR praxis. 
For purposes of this study we define CSR as voluntary operational goals and activities that aim to advance a social or environmental agenda beyond the interest of the firm and beyond legal requirements $[1,3]$. In contrast to some scholarship, we distinguish sustainability from CSR, as a more macro concept that includes visioning, strategizing, and taking action towards a world with enough access to resources for all, a healthy biosphere, and other broad spectrum ideals [4]. CSR and sustainability overlap of course, and we employ a third term, company responsibility (CR), as an umbrella concept to encompass both.

\section{CONCEPTUAL FRAMEWORK}

\subsection{Conventional research perspective}

Several major reviews of the CSR literature concur in finding a small but positive effect of CSR programs on company financial performance (CFP) $[1,5,6]$, in addition to the company and employee benefits mentioned above. Yet despite these valuable findings, the responsible mechanisms or linkages are unclear, largely because they involve internal organizational processes that are not well understood [2, 6]. Indeed, Aguinis and Glavas [1] found employee-level perceptions and actions addressed in only $4 \%$ of the 690 papers and chapters they reviewed. Further, most studies rely on large, cross-sectional, firm-level datasets that compare antecedents and outcomes [6]. Cross-sectional research, while valuable, is unable to provide insight into the ongoing processes of change and development that underlie organizations' continual search for positive CR results.

A separate issue with this literature is that 'systems theory' is frequently invoked but rarely defined. We presume the reason to be that only one foundational theory of systems is assumed, that based in the positivist, linear, and reductionist assumptions of traditional, neoclassical management theory. There is a search for causality and a drive for a unifying, generalizable theory. For purposes of this paper we label this as the 'conventional' approach in the CSR research.

\subsection{Complexity theory perspective}

There are dissenting voices in CSR discourse as well, voices critiquing conventional approaches and urging alternative directions. Margolis and Walsh's [7] call to transcend the economic imperative of neoclassical organization theory in CSR research remains a strong beacon today. They recognize that existing management theories 'may be too simplistic and static to fully explain the complexity of the paradoxical demands inherent in the management of sustainability' [8]. Such critiques and calls point toward a radically different approach, that of complexity theory and complex adaptive systems (CAS).

We refer the reader to other, fuller explanations of complexity theory and its application to management and sustainability $[9,10]$. The primary premise is that individual and idiosyncratic actions of line level actors are the core and central process of system development. This focus on the individual as an individual is precisely what we need to get to the hard-to-reach employee-process level of CR adoption. The problem, and perhaps one reason it has not been much employed to date, is that complexity theory assumptions are incommensurable with those of conventional systems research. The two theories cannot be selectively spliced onto one another. This is because CAS are non-linear, self-organizing, and highly unpredictable. They are continually created in the moment by many types of actors whose directed self-interest 
brings them into contact with many other actors. The resultant melee is uncontrollable, but regularities do emerge over time through coevolution and emergence [11]. Each system and context is unique, such that generalizing across organizations, geographies, and cultures is not warranted [12]. Henceforth we label this complexity theory perspective as the 'complexity' approach.

\subsection{High performance work systems}

An established entrée to employee-level social processes is that of Strategic Human Resource Management (SHRM). Beginning in the 1980s, SHRM initiatives, known as High Performance Work Systems (HPWS), Modern Working Practices and other monikers, have been successful in increasing employees' knowledge, skills, empowerment and motivation to contribute 'discretionary effort' [2]. Initiatives involve customized combinations of flatter hierarchies, increased employee participation, flexible work schedules including working from home, redesigned office spaces, reduced supervision, individual control of tasks, and revised incentive systems linked to creativity and productivity [13, 14]. Analyses of HPWS generally concur in finding a clear link with company financial performance (CFP) [15], though not without exceptions [16]. Henceforth we inclusively refer to this type of program as HPWS.

Interestingly, HPWS programs have also been linked with CSR and sustainability through the mediator of Company Social Performance (CSP) [2, 17]. CSP is an overall snapshot of the firm's social posture [18], and includes both internal employee wellbeing and outward-facing service to community. By focusing on employee wellbeing, HPWS is both a significant part of CR and a window to its micro-level adoption. As with CSR research, however, this research stream is limited by its unacknowledged embeddedness within Conventional assumptions. Most studies are cross-sectional [12], lack consensus on measures and methods [19], and provide little insight into the relationships and processes that link employee attitudes with CSP and CFP [20]. For these reasons, a complexity approach using primary data and a longitudinal perspective is called for, to better understand the 'black box' of HPWS employee dynamics [20,21]. In the empirical study that follows we problematize the unclarified use of 'systems theory,' take a longitudinal perspective and a microprocess level of analysis, and focus on employees as lynchpins between HPWS and CSR intentions and achievement.

\section{CASE STUDY AND HYPOTHESES}

Our empirical project was a two-year quasi-ethnographic case study of a public sector organization in Wales. As we began, the home office of the organization was rolling out a comprehensive HPWS project as a follow-on to an extensive strategic re-view and re-vision in the previous year. The present study focused on employees' perceptions and responses to the rollout through two surveys administered at three time points: as the rollout was beginning, as the rollout ended six weeks later, and one year after the rollout (see table). Competing hypotheses were developed from conventional and complexity perspectives, which enabled us to compare theoretical predictions in a live setting. The low Ns reflect the small size of the organization, and while they result in low statistical power they also represent very high response rates, $70 \%$ or better. Although the surveys were anonymous, the participants at earlier time points continued to participate later. Time 3 was much larger as participation spread beyond the organization's home office. 
Table 1: Two surveys and their administration.

\begin{tabular}{lllll}
\hline \multirow{2}{*}{ Title } & Source & $\begin{array}{l}\text { Time 1 (t1), } \\
\text { May 2014 }\end{array}$ & $\begin{array}{l}\text { Time 2 (t2), } \\
\text { June 2014 }\end{array}$ & $\begin{array}{l}\text { Time 3 (t3), } \\
\text { June 2015 }\end{array}$ \\
\hline Zinger Survey & $\begin{array}{l}\text { Single-item feelings of } \\
\text { wellbeing }\end{array}$ & $\checkmark$ & $\checkmark$ & $\checkmark$ \\
Attitude Survey & Validated attitude scales & & $\checkmark$ & $\checkmark$ \\
& & $\mathrm{N}=13$ & $\mathrm{~N}=16$ & $\mathrm{~N}=36$ \\
\hline
\end{tabular}

\subsection{Hypotheses}

\subsubsection{Employee wellbeing}

The first survey, nicknamed the Zinger, was a simple, quick survey designed to capture employees' spontaneous responses to the HPWS project at the three time points shown above. The survey elicited employees' self-report on single items representing eight feelings in the workplace on a 5-point Likert scale: these were creativity, productivity, collegiality, collaboration, job satisfaction, autonomy, engagement, and positive morale.

Interestingly, prior conventional research has shown an increase in most of these feelings following CSR and HPWS initiatives (see Introduction and Section 2.3). We have no reason to expect a different result here, between $\mathrm{t} 1$ and $\mathrm{t} 2$. Less researched, but of great interest, is what happens between $\mathrm{t} 2$ and $\mathrm{t} 3$ of the study. We reasoned that conventional approaches would predict a sustained increase between $\mathrm{t} 2$ and $\mathrm{t} 3$ as well. In a linear systems framework each of the eight feelings is an independent variable that is stable and predictable over time. It would therefore respond consistently to the same stimulus; in this case, the rollout and incorporation of HPWS changes into company routines.

Complexity theory, on the other hand, does not isolate pairwise relationships and look for longitudinal causality. Indeed, linear causality is a non sequitur in CAS. Instead, the coevolutionary dynamics and continual self-organization of the system means that any one actor could be both influencing and being influenced by another at the same time. Further, feelings may change, dissolve, or evolve in unpredictable ways in CAS. They are social constructions amongst those party to them at the moment [22]. Hence, from a complexity perspective, we do not expect a linear trend in the longitudinal Zinger Survey results. To summarize:

\section{Hypothesis 1a: The three time points measured in the HPWS project will show improve- ment in a linear relation over time. \\ Hypothesis $1 b$ : The three time points measured in the HPWS project will not follow a linear trend.}

\subsubsection{Employee attitudes}

The second survey, called the Attitude survey, was more in-depth, designed to study attitudinal changes that have been previously related to HPWS projects and CSR. We extracted four items each from six validated attitude scales (in order to keep the survey to a manageable length), as shown below. Respondents were asked to rate the strength of their agreement with each statement on a 4-point Likert Scale. 
Table 2: Attitude survey: constructs and items, (r) denotes reverse scoring.

\begin{tabular}{|c|c|c|}
\hline \# & Attitude Construct & Item \\
\hline 1 & & I have ideas about how to improve this company. \\
\hline 2 & 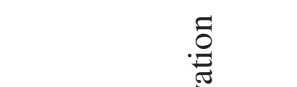 & $\begin{array}{l}\text { People sometimes talk with me about their new ideas and } \\
\text { initiatives. }\end{array}$ \\
\hline 3 & בे & A group of us are trying out a new idea here. \\
\hline 4 & $\Xi$ & I try to promote new ideas and initiatives to others. \\
\hline 5 & & I feel that I have a number of good qualities. \\
\hline 6 & & All in all, I am inclined to feel that I am a failure. (r) \\
\hline 7 & $\Psi$ ब & I am able to do things as well as most people. \\
\hline 8 & $\ddot{\infty}$ & I take a positive attitude towards myself. \\
\hline 9 & & I am proud to be an employee of this company. \\
\hline 10 & $\tilde{\Xi ี \Xi} \approx$ & In general, this company's goals are similar to my own. \\
\hline 11 & 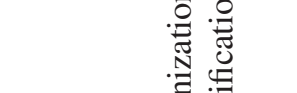 & $\begin{array}{l}\text { I find it difficult to agree with this company's policies on } \\
\text { matters familiar to me. (r) }\end{array}$ \\
\hline 12 & कृ & $\begin{array}{l}\text { I find that my values and the values of this company are } \\
\text { very similar. }\end{array}$ \\
\hline 13 & & I am a person who cares about sustainability. \\
\hline 14 & & Let future generations solve their own problems. (r) \\
\hline 15 & 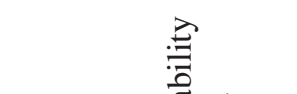 & $\begin{array}{l}\text { The positive benefits of economic growth outweigh any } \\
\text { negative environmental or social impact. (r) }\end{array}$ \\
\hline 16 & 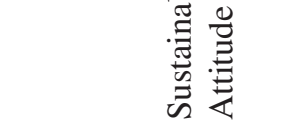 & $\begin{array}{l}\text { I don't buy consumer products if I know that unethi- } \\
\text { cal, unjust, or harmful practices were involved in their } \\
\text { production. }\end{array}$ \\
\hline 17 & & I feel there is never enough time to get things done. (r) \\
\hline 18 & $\tilde{\omega}_{0}^{\infty}$ & My work role tends to interfere with my personal life. (r) \\
\hline 19 & 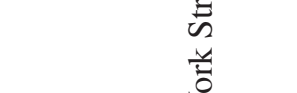 & $\begin{array}{l}\text { The amount of work I do interferes with the quality I } \\
\text { want to maintain. (r) }\end{array}$ \\
\hline 20 & 3 & I do not get enough resources to be effective in my job. (r) \\
\hline 21 & & If I make plans, I generally succeed in executing them. \\
\hline 22 & ఫ్ర్ల & $\begin{array}{l}\text { If I have a failure the first time, I keep working at it until } \\
\text { it is going better. }\end{array}$ \\
\hline 23 & $\stackrel{E}{E}$ & I am usually able to solve problems well in my life. \\
\hline 24 & $\frac{\Phi}{\stackrel{L}{\Phi}}$ & $\begin{array}{l}\text { I do not start learning new things if I think they are too } \\
\text { difficult. (r) }\end{array}$ \\
\hline
\end{tabular}

Since this survey was concerned with multi-item variables, our first hypothesis was a test of their reliability in representing each variable, and their consistency in doing so at both time measures. A complexity perspective would point out that even this simple test belies conventional assumptions without acknowledgement as such. In complex systems, attitudes are socially constructed in dynamic local contexts and likely to change as relationships and contexts change over time. While conventional linear systems theory would generally predict 
reliability and consistency at least to some degree, no consistent agreement within any particular set of value statements in CAS would be expected. Hence:

Hypothesis 2a: Each set of four items from the six attitude constructs are both internally consistent and consistent over time.

Hypothesis 2b: Each set of four items from the six attitude constructs are neither internally consistent and nor consistent over time.

\subsubsection{Individual survey items}

We also wanted to examine possible changes in individual items of the attitude survey on a longitudinal basis. We reasoned that if a survey item was related to the HPWS intervention, and if the item gained strength in responses between $\mathrm{t} 2$ and $\mathrm{t} 3$, then that item would likely be related to company responsibility. The question was, what would a conventional perspective predict about whether and which items would change, and how would these predictions vary in a Complexity approach? First, since all the items are associated with constructs that reflect the aims of CR, conventional theory would predict that all items would improve between $\mathrm{t} 2$ and $\mathrm{t} 3$ in a linear trend. Secondly, although study of attitudinal changes in complex systems is largely lacking in CR, we believe that survey items indicating individuals' active engagement and participation in the system would be expected to change more over time than passive expressions of ideas and beliefs. In sum:

Hypothesis 3a: All 24 items of the attitude survey will rise between 2 and t3.

Hypothesis 3b: Survey items that involve action and interaction will rise between 2 and $t 3$.

\section{RESULTS}

\subsection{Hypothesis 1}

Hypothesis 1 was tested using the chi-square test of association. A non-parametric approach was called for due to the small and unequal sample sizes and the ordinal nature of the data. The chi square reveals the tendency of the modes of each assessment, which we considered a reasonable way to test the hypotheses.

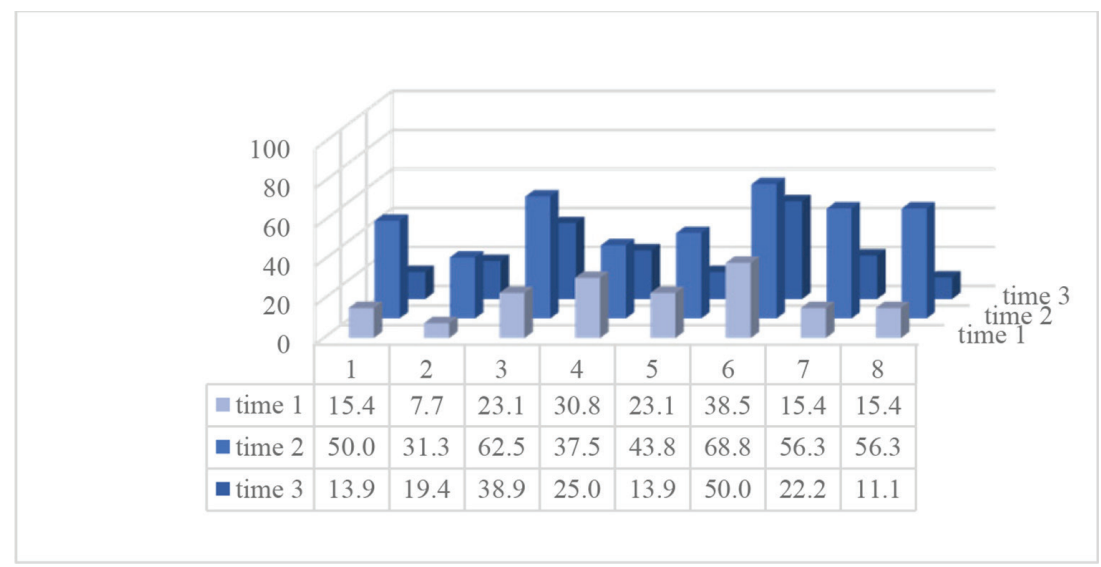

Figure 1: Bar chart showing strength of positive responses in the Zinger survey at $\mathrm{t} 1, \mathrm{t} 2$, and $\mathrm{t} 3$. 
Table 3: Zinger survey: Chi-square test of association with $p$-values and Cramer's V effect size.

\begin{tabular}{lrllll}
\hline Zinger Item & \multicolumn{1}{c}{$X^{2}$} & $d f$ & $\mathrm{~N}$ & $p$ & $\mathrm{~V}$ \\
\hline 1 Creativity & 19.994 & 6 & 65 & 0.003 & 0.392 \\
2 Productivity & 8.180 & 4 & 65 & 0.085 & 0.251 \\
3 Collegiality & 7.312 & 6 & 65 & 0.293 & 0.237 \\
4 Collaboration & 6.137 & 6 & 65 & 0.408 & 0.217 \\
5 Job Satisfaction & 10.386 & 4 & 65 & 0.034 & 0.283 \\
6 Autonomy & 7.674 & 6 & 65 & 0.263 & 0.243 \\
7 Engagement & 10.790 & 6 & 65 & 0.095 & 0.288 \\
8 Positive Morale & 19.401 & 6 & 65 & 0.004 & 0.386 \\
\hline
\end{tabular}

Figure 1 shows an uptick in all Zinger feelings between $t 1$ and $t 2$, signaling a rise in these aspects of employee wellbeing as the HPWS project rolled out. This result agrees with the conventional approach and most of the literature that has found that employee wellbeing improves in the short run. Quite unexpected, however, were the results for $\mathrm{t} 3$, namely that all eight Zinger items then decreased at $\mathrm{t} 3$ relative to $\mathrm{t} 2$. Chi-square results (Table 3 ) show that this peaked pattern was significantly different than that which would be expected by chance for five of the eight Zinger feelings (shaded): creativity, productivity, job satisfaction, engagement, and morale. Using Cramer's $V$ as a measure of effect size, the significant results showed a moderate effect which was only a bit larger than the effect seen with the remaining items. It suggests the possibility that there may be other significant effects too small to detect with the low power of our study.

\subsection{Hypothesis 2}

We found no significant measures of reliability for any of the assessed attitude constructs in our data. This result shows a complete lack of support for Hypothesis $2 \mathrm{a}$ and full support for Hypothesis $2 \mathrm{~b}$. To consider the alternative possibility that in fact there were attitudinal factors present, just not those we had predicted, we also conducted an exploratory factor analyses at both $\mathrm{t} 2$ and $\mathrm{t} 3$. There was indeed a factor structure in evidence at $\mathrm{t} 2$, but we could find little logic to connect the items involved. There was another but completely different factor structure at $\mathrm{t} 3$. Hence, we surmised that there was unlikely to be any meaningful overt or latent constructs in our data. Perhaps these data were confounded by the limitations of our sample, but these results may also inform revisions to our theories.

\subsection{Hypothesis 3}

Hypothesis 3 was analysed with the chi-square test, again due to the small and variable sample, and the use of an ordinal scale. Results shown in Table 3 indicate that 3 of the 24 items rose significantly between $\mathrm{t} 2$ and $\mathrm{t} 3$. These were:

\#16: I don't buy consumer products if I know that unethical, unjust, or harmful practices were involved in their production;

\#20: If I make plans, I generally succeed in executing them;

\#21: I do get enough resources to be effective in my job (after reverse scoring). 
Table 4: Attitude Survey: Chi-square test of association with $p$-values and Cramer's V effect size.

\begin{tabular}{lrllll}
\hline Attitude Item & $X^{2}$ & $d f$ & $\mathrm{~N}$ & $p$ & $\mathrm{~V}$ \\
\hline 1 & 2.195 & 2 & 60 & 0.334 & 0.191 \\
2 & 0.526 & 2 & 63 & 0.769 & 0.091 \\
3 & 1.538 & 3 & 61 & 0.673 & 0.159 \\
4 & 2.440 & 2 & 62 & 0.295 & 0.198 \\
5 & 0.549 & 1 & 63 & 0.459 & 0.093 \\
6 & 0.929 & 2 & 63 & 0.628 & 0.121 \\
7 & 2.982 & 3 & 63 & 0.394 & 0.218 \\
8 & 3.846 & 2 & 63 & 0.146 & 0.247 \\
9 & 0.765 & 2 & 63 & 0.682 & 0.110 \\
10 & 1.413 & 2 & 63 & 0.493 & 0.150 \\
11 & 1.452 & 2 & 63 & 0.484 & 0.152 \\
12 & 2.249 & 2 & 63 & 0.325 & 0.189 \\
13 & 0.870 & 2 & 62 & 0.647 & 0.118 \\
14 & 2.590 & 3 & 63 & 0.459 & 0.203 \\
15 & 1.334 & 2 & 62 & 0.513 & 0.147 \\
16 & 6.046 & 2 & 62 & 0.049 & 0.312 \\
17 & 2.058 & 3 & 63 & 0.560 & 0.181 \\
18 & 3.888 & 3 & 62 & 0.274 & 0.250 \\
19 & 1.438 & 3 & 63 & 0.697 & 0.151 \\
20 & 8.007 & 3 & 63 & 0.046 & 0.357 \\
21 & 12.806 & 2 & 63 & 0.002 & 0.451 \\
22 & 0.774 & 2 & 63 & 0.679 & 0.111 \\
23 & 3.954 & 2 & 63 & 0.138 & 0.251 \\
24 & 3.115 & 3 & 63 & 0.374 & 0.222 \\
\hline
\end{tabular}

Hypothesis 3a was partially supported: 3 of the 24 individual survey items rose significantly from $t 2$ to 3 . It appears that there was not a strong enough effect of the HPWS project over time to influence all attitude items to change as predicted over the longer term of one year. Hypothesis $3 \mathrm{~b}$ was rather more strongly supported but, in our view, due to a radically different logic. Hypothesis $3 \mathrm{~b}$ was based on the argument that items indicating action and interaction would be most likely to exhibit a significant increase at $\mathrm{t} 3$. Of all the 24 items in the survey, we believe items 3, 7, 16, 20,21, 22, 23, and 24 fall into this category. Therefore, the fact that items 16,20, and 21 did increase significantly does lend support to the idea that action-oriented actors do have more impact in a complexity environment than those who may have equally strong beliefs without engaging others.

\section{DISCUSSION AND CONCLUSION}

Our study and data analysis have shown that conventional linear systems analysis was inadequate alone to explain internal sustainability adoption processes in the public sector organization we studied. Specifically, the spike-and-return pattern found in the longitudinal Zinger Survey results of Hypothesis 1 defies the expectation of ongoing linear improvement 
in the employee wellbeing over the long term. Also, the universality of the decline in wellbeing indicators at $\mathrm{t} 3$ begs further investigation. In Hypothesis 2, the complete absence of either expected or latent attitudes could be due to a failure of conventional approaches to yet identify instrumental feelings and attitudes in employee wellbeing, or it could be that the nonlinear social construction process is not well enough understood in complexity approaches to CSP to make accurate predictions. Supporting the latter possibility are Hypothesis 3 results, where the complexity perspective indicated the importance of social action and interaction as the source of productive systemic change, over and above tacit beliefs and attitudes. Linear systems theory had no alternative explanation for these results.

In sum, perhaps the most reasonable statement that can be made is that the taken-forgranted dominance of conventional systems perspectives in CR research needs to be rethought. The neoclassical, positivist, and reductionist model of employee behavior is certainly not the only and may not be the best way to study internal organizational shifts towards sustainability. Indeed, its exclusive use may actually obscure what we're now looking for, a more nuanced understanding of employees' idiosyncratic processes related to sustainability adoption. Complexity theory, new and largely untried in the CSR field to date, offers a compelling addition.

We propose that conventional and complexity approaches are distinct, incommensurable modes of company responsibility. CSR is derived in the conventional approach and refers to operations- and firm-level CR objectives such as resource optimization, initiative implementation, and achievement of all manner of tangible responsibility objectives. On the other hand, sustainability is derived in complexity theory and CAS. Sustainability is a guiding concept for the mutual health and resilience of the most macro-level systems, including the biosphere and human society and enterprise [23]. We associate this concept and ontology with 'sustainability thinking,' [24] which is the visioning, collaborating, and adapting that underlie the achievement of temporary markers of CSR progress. Pogutz and Winn [25] have coined the term, 'sustainability fit,' as the condition in which a company can 'adapt and align dynamically [i.e. coevolve] with the resilience of the ecosystem within which it is embedded.' We extend their notion to introduce the idea of 'sustainability fitness' via complex systems principles, to describe the mindset and capabilities for balanced adaptation in the ongoing search for earthwise sustainability. CSR can be managed and stewarded, but sustainability must be nurtured, in an ongoing co-operative process among equals.

\subsection{Limitations and alternative explanations}

There are several issues with our study. Although this longitudinal study achieved high response rates, the sample size was small and as such analysis was restricted to non-parametric methods. Despite the small power present, some significant results were found warranting further research with larger samples. The Hawthorne effect and regression to the mean may have been in play in the spike-and-return phenomenon. Also, what are called 'confounding factors' in positivist research, and considered 'as-yet unknown complex processes' in CAS, are likely to have had an effect on our results.

\subsection{Future research}

The project for future research is not only to tease out finer and finer antecedents, moderators, mediators, etc., in CSR models. This agenda is firmly and myopically situated in conventional positivist and reductionist ontology. It is equally important to operationalize 
complexity theory and apply it through a variety of methods to dig deeper into the 'black box' of human, idiosyncratic micro-processes in sustainability fitness. Finally, it is important to take the birds-eye view at times, seeking not to integrate, and therefore, obfuscate the unique perspectives offered by each theory, but to consider them simultaneously for informative insights and ideas [26]. In this way, the business and management academy can maintain and increase its relevance in this desperately crucial field.

\section{REFERENCES}

[1] Aguinis, H. \& Glavas, A., What we know and don't know about corporate social responsibility: a review and research Agenda. Journal of Management 38(4), pp. 932-968, 2012. https://doi.org/10.1177/0149206311436079

[2] Applebaum, E., Bailey, T., Berg, P. \& Kalleberg, A.L., Manufacturing Advantage: Why High-Performance Work Systems Pay Off. Ithica, NY: Cornell University Press, 2000.

[3] Jin Suh, Y., The role of relational social capital and communication in the relationship between csr and employee attitudes: a multilevel analysis. Journal of Leadership \& Organizational Studies, 23(4), pp. 1-14, 2016.

[4] Hawkin, P., Lovins, A. \& Lovins, H., Natural Capitalism: The Next Industrial Revolution, London: Earthscan, 2010.

[5] Peloza, J., The challenge of measuring financial impacts from investments in corporate social performance. Journal of Management, 35(6), pp. 1518-1541, 2009. https://doi.org/10.1177/0149206309335188

[6] Wang, H., Corporate social responsibility: an overview and new research directions. Academy of Management Journal, 59(2), pp. 534-544, 2016. https://doi.org/10.5465/amj.2016.5001

[7] Margolis, J. \& Walsh, J., Misery loves companies: rethinking social initiatives by business. Administrative Science Quarterly, 48, pp. 268-305, 2003. https://doi.org/10.2307/3556659

[8] Starik, M. \& Kanashiro, P., Toward a theory of sustainability management: uncovering and integrating the nearly obvious. Organization and Environment, 26(1), pp. 7-30, 2013. https://doi.org/10.1177/1086026612474958

[9] Anderson, P., Complexity theory and organization science. Organization Science, 10(3), pp. 216-232, 1999. https://doi.org/10.1287/orsc.10.3.216

[10] McKelvey, B., Quasi-natural organization science. Organization Science, 8(4), pp. 352 380, 1997. https://doi.org/10.1287/orsc.8.4.351

[11] Porter, T., Coevolution as a research framework for organizations and the natural environment. Organization and Environment, 19(4), pp. 479-504, 2006. https://doi.org/10.1177/1086026606294958

[12] Robone, A., Jones, A. \& Rice, N., Contractural conditions, working conditions and their impact on health and well-being. European Journal of Health Economics, 12, pp. 429-444, 2011. https://doi.org/10.1007/s10198-010-0256-0

[13] Pfeffer, J., The Human Equation: Building Profits by Putting People First, Cambridge, MA: Harvard Business Press, 1998. 
[14] Huselid, M., The impact of human resource management practices on turnover, productivity, and corporate financial performance. Academy of Management Journal, 38(3), pp. 635-672, 1995.

https://doi.org/10.2307/256741

[15] Rothenberg, S., Hull, C. \& Tang, C., The impact of human resource management on corporate social performance strengths and concerns. Business and Society, pp. 1-28, 2015.

[16] Oana, G. \& Shahrazad, H'., Does civil society create social entrepreneurs?. In Ideas, ed. Federal Reserve Bank of St. Louis, 2013, available at: http://anale.steconomiceuoradea. ro/volume/2013/n1/069.pdf.

[17] Sheehan, M., Garavan, T. \& Carbery, R., Innovation and human resource development (HRD). European Journal of Training and Development, 38(1/2), pp. 2-14, 2014. https://doi.org/10.1108/EJTD-11-2013-0128

[18] Barnett, M., Stakeholder influence capacity and the variability of financial returns to corporate social responsibility. Academy of Management Review 32(3), pp. 794-816, 2007.

https://doi.org/10.5465/AMR.2007.25275520

[19] Combs, J., Hall, A. \& Ketchen, D., How much do high-performance work practices matter? a meta-analysis of their effects on organizational performance. Personnel Psychology, 59(3), pp. 501-528, 2006. https://doi.org/10.1111/j.1744-6570.2006.00045.x

[20] Ko, J. \& Smith-Walter, A., The relationship between hrm practices and organizational performance in the public sector: focusing on mediating roles of work attitudes. International Review of Public Administration, 18(3), pp. 209-231, 2013. https://doi.org/10.1080/12294659.2013.10805270

[21] Hull, C. \& Rothenberg, S., Firm performance: the interactions of corporate social performance with innovation and industry differentiation. Strategic Management Journal, 29, pp. 781-789.

https://doi.org/10.1002/smj.675

[22] Stacey, R., Complex Responsive Processes in Organizations: Learning and Knowledge Creation, London: Routledge, 2001.

[23] Waddock, S., Leading Corporate Citizens: Vision, Values, Value-Added, 3 edn., New York: McGraw Hill, 2009.

[24] Porter, T. \& Derry, R., Sustainability and business in a complex world. Business and Society Review, 117(1), pp. 33-54, 2012. https://doi.org/10.1111/j.1467-8594.2012.00398.x

[25] Pogutz, S. \& Winn, M., Cultivating ecological knowledge for corporate sustainability: barilla's innovative approach to sustainable farming. Business Strategy and the Environment, 25(6), pp. 435-448, 2016. https://doi.org/10.1002/bse.1916

[26] Espinoza, A. \& Porter, T., Sustainability, complexity and learning: insights from complex systems approaches. The Learning Organization, 18(1), pp. 54-72, 2011. https://doi.org/10.1108/09696471111096000 